\title{
Research on psychosocial risks in the context of intervention and rescue activities in toxic / flammable / explosive environments
}

\author{
Izabella Kovacs ${ }^{I}$, Andrei Lucian Gireadă $\breve{I}^{I}$, Alin Irimial ${ }^{I}$ and Laurențiu Munteanu ${ }^{1}$ \\ ${ }^{I}$ National Institute for Research and Development in Mine Safety and Protection to Explosion- \\ INSEMEX Petroşani, 32-34 G-ral Vasile Milea Street, Postcode: 332047, Petroşani, Hunedoara \\ County, Romania
}

\begin{abstract}
Work implies interaction of several components such as equipment, work environment, work load and human factor. Prevention of work accident and occupational diseases is mainly based on knowledge and assessment of occupational risks associated with each workplace. Psychosocial risks are usually caused by stress, thus being greatly influenced by individual perceptions. Identifying psychosocial risks is based on the analysis of individual reactions to external factors and activities. Worldwide, work related stress is seen as a major present-day challenge, faced by occupational health and safety specialists. Considered at organizational level and not as individual issues, psychosocial risks and stress can be managed to the same extent as any other occupational health and safety risk. The growing issue of protecting emergency workers against occupational health and safety risks has been highlighted as a priority by many experts. Demands on intervention and rescue personnel, as well as occupational health and safety risks will increase as they face larger events both in number and magnitude and severity. The current paper will summarize key issues related to work-related stress and will discuss how stress at work can be best managed in the context of intervention and rescue activities in toxic / flammable / explosive environments.
\end{abstract}

\section{Introduction}

Work involves the combination of certain components, namely work equipment, work environment, workload and the human factor represented by the worker.

During work, the worker is subjected to both physical and psychosocial demands that are dependent on the type of activity performed. Delimitation of these two types of work demands is purely theoretical, there are causal links between the two, respectively, abnormal demands diminish not only the mental capacity but also the physical one with which it is associated.

Perception of work demands as normal means that work components, mentioned above, must meet certain conditions. Referring to the human factor, as central element of work, we can list: skills, knowledge, abilities and other individual characteristics (such as experience, emotional stability, proper motivation, physical and psychological health, etc.). 
Psychosocial risk at work, as defined by the International Labour Organization (ILO), refers to the likelihood that certain aspects of design, organization and management of work, along with their social and environmental contexts, will have physical, psychological and social negative consequences. If psychosocial risks associated with a workplace are considered organizational issues and not just individual's issues, they can be managed in the same way as any other risk to the safety and health at work.

In Europe, according to the OSHA (Occupational Safety and Health Administration), among work-related health problems, stress ranks second in frequency of reporting. A quarter of European employees felt that they were facing stress for most of their work schedule, and a quarter of them said that work had a negative effect on their health. Almost half of employed people in Europe felt that stress was not managed effectively in their workplace. This is because, despite the fact that about $80 \%$ of managers were concerned about work-related stress, less than a third of companies had implemented specific stress-related procedures.

The European survey on new and emerging risks (ESENER) also includes psychological risk factors reported by European jobs, summarized in Table 1. [1]

Table 1. Reported psychosocial risk factors (\% of units) - ESENER 2019 [1]

\begin{tabular}{|l|c|}
\hline Pressure due to time constraints & $45 \%$ \\
\hline $\begin{array}{l}\text { Poor communication or cooperation within the } \\
\text { organisation }\end{array}$ & $18 \%$ \\
\hline Fear of job loss & $13 \%$ \\
\hline $\begin{array}{l}\text { Having to deal with difficult customers, patients, } \\
\text { pupils etc. }\end{array}$ & $60 \%$ \\
\hline Long or irregular working hours & $22 \%$ \\
\hline
\end{tabular}

According to the same European agency, the figures for Romania showed that half of Romanian employees considered cases of work-related stress to be common in their workplace, while less than the other half considered that such cases were rare.

If occupational stress extends over a long period of time, this situation can lead to a state of physical, emotional and mental exhaustion called burnout. In addition to mental health problems, experiencing prolonged stress at work can lead to serious physical health problems, such as cardiovascular or musculoskeletal disorders.

\section{Work-related stress: causes and consequences}

A number of theorists have tried to find the mechanisms and causes of stress in the context of work activities. The most influential of these theories, which are also the basis of intervention methods to prevent and reduce occupational stress and its effects are summarised below:

- Person-environment fit: the theory states that stress can occur because of the mismatch between the individual's abilities, resources and skills on one hand, and work requirements, on the other. 


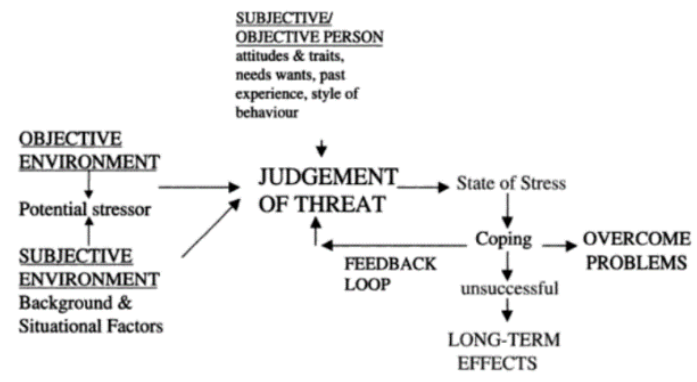

Fig. 1. Person-environment fit theory [2]

- The requirements-control model developed by Karasek suggests that the level of professional stress is determined by the lack of balance between job requirements and employee autonomy in solving requirements. According to the theoretical model, the level of control that an employee has over his work environment is an element of defining influence, on one hand on health of that person and on the other hand on the desire for active learning. [3]

Subsequently, the theory also included a social dimension, namely social support, stating that social support can moderate the negative impact of stress at work on physical and mental health of workers.

- The effort-reward imbalance model assumes that presence of an imbalance between effort put into and low reward is likely to cause, in exposed individuals, negative emotions and repeated and/or prolonged reactions to stress. On the contrary, a mutually beneficial relationship within the organizational framework, embodied in appropriate social rewards, can lead to positive emotions that can help promote well-being and health of members of the organization. [4]

- The transactional model of stress and coping, developed by Lazarus and Folkman, focuses on how unwanted events can cause stressful episodes in the context of humanenvironment transactions. According to transactional theory, coping lies in the cognitive, physiological and behavioural effort to reduce/minimize, eliminate, master or tolerate internal or external demands in the context of person - organizational environment transaction, demands that exceed real personal resources/possibilities [5]. But the traumatic nature of an emotionally disruptive event is always the result of a subjective interpretation of this event by the individual and is not dependent solely on objective indications of the event. Cognitive assessment made by the worker of the perceived relationship between demands and abilities can be influenced by a number of factors: personality, situational characteristics, coping skills, previous experiences and any current state of stress.

If we refer to the main sources of psychosocial stress, they are summarized in the table below (table 2)

Table 2. Main sources of psychosocial stress in organizational environments [6]

\begin{tabular}{|l|l|}
\hline \multicolumn{1}{|c|}{ Risk } & \multicolumn{1}{|c|}{ Conditions that define the risk } \\
\hline The activity it self & $\begin{array}{l}\text { Monotony of work, short work cycles, fragmented, } \\
\text { unnecessary work, insufficiently used skills, high } \\
\text { degree of uncertainty, permanent contact with clients, } \\
\text { patients, difficult students, etc. }\end{array}$ \\
\hline
\end{tabular}




\begin{tabular}{|c|c|}
\hline Workload and work pace & $\begin{array}{l}\text { Over / undersized workload, pace determined by } \\
\text { automation, high levels of time pressure and } \\
\text { permanent deadline pressure. }\end{array}$ \\
\hline Work time & $\begin{array}{l}\text { Working in shifts, night shifts, inflexible work } \\
\text { schedule, unforeseen working time, extended or } \\
\text { maladapted work schedule. }\end{array}$ \\
\hline Control & $\begin{array}{l}\text { Low degree of participation in decision-taking, lack } \\
\text { of control over workload, work pace, working in } \\
\text { shifts, etc. }\end{array}$ \\
\hline $\begin{array}{l}\text { Work environment and } \\
\text { equipment }\end{array}$ & $\begin{array}{l}\text { Low availability, inadequacy or inadequate } \\
\text { maintenance of work equipment; unsuitable } \\
\text { environmental conditions, such as lack of space, low } \\
\text { lighting and excessive noise. }\end{array}$ \\
\hline $\begin{array}{l}\text { Position and } \\
\text { organizational culture }\end{array}$ & $\begin{array}{l}\text { Poor communication, low level of support for } \\
\text { problem solving and personal development, lack of } \\
\text { leadership support; lack of definition for } \\
\text { organizational objectives or agreement upon them. }\end{array}$ \\
\hline $\begin{array}{l}\text { Interpersonal } \\
\text { relationships at work }\end{array}$ & $\begin{array}{l}\text { Social or physical isolation, poor relationships with } \\
\text { superiors, interpersonal conflicts, lack of social } \\
\text { support, harassment, intimidation, inappropriate } \\
\text { leadership style and violence from third parties. }\end{array}$ \\
\hline $\begin{array}{l}\text { Role played in the } \\
\text { organization }\end{array}$ & $\begin{array}{l}\text { Role ambiguity, conflicting roles and responsibility } \\
\text { for people. }\end{array}$ \\
\hline Career development & $\begin{array}{l}\text { Career stagnation and uncertainty, low wages, } \\
\text { under/overpromotion, job insecurity and low social } \\
\text { value of work. }\end{array}$ \\
\hline $\begin{array}{l}\text { Family time/work time } \\
\text { interface }\end{array}$ & $\begin{array}{l}\text { Antagonistic requirements in the personal- } \\
\text { professional life relationship, low level of support at } \\
\text { home and problems related to the fact that both } \\
\text { partners are in the field of work (double career). }\end{array}$ \\
\hline
\end{tabular}

When talking about the sources of stress, we need to consider issues related to work environment, personal factors and the family environment. In addition to these general sources of stress, common to all workplaces, in the intervention and rescue activities the following situations also represent specific challenges:

- Being part of a collective crisis;

- Repeated exposure to grim experiences, such as manipulation of lifeless bodies, confrontation with multiple victims, strong emotions and tumultuous stories of those affected;

- Performing physically difficult, exhausting or dangerous tasks;

- $\quad$ Lack of sleep and the feeling of chronic fatigue, caused by demanding tasks;

- Dealing with the perceived inability to ever do enough;

- Confrontation with moral and ethical dilemmas;

- $\quad$ Exposure to anger and apparent lack of gratitude of affected people;

- The feeling of frustration given by policies and decisions of superiors within the organization.

Rescuers are exposed to unusual personal demands in their desire to help meet the needs of survivors of a critical event (providing first aid, approaching the centre of the disturbing event, and last but not least confronting emotionally disturbed and physically injured people).

The ability to avoid negative stressors in the work environment is significantly reduced for intervention and rescue personnel who often participate in overwhelming events. 
Interaction with many victims, injured people and their families, high responsibility for people's lives, violence at work, irregular and unpredictable working hours and severe time pressure, all represent dangers that can lead to serious emotional overload for intervention and rescue personnel. In addition, major accidents and incidents usually attract intense media coverage, and this can add extra stress for rescuers. The psychological burden can also be linked to moral dilemmas when decisions need to be made about balancing the need to help others at risk for the rescuer's personal safety. Sometimes intervention and rescue personnel may face unrealistic public expectations, even in situations where occupational health and safety risks outweigh the potential benefits of the intervention.

Among intervention and rescue personnel, symptoms or even mental disorders can result from the strong impressions and feelings they have to endure when faced with death and destruction, as well as the injuries, pain, suffering and despair of survivors. Intervention and rescue personnel face enormous psychological demands, are burdened with responsibility for the lives of others, and the feeling that any mistake or failure could lead to someone's death causing feelings of guilt that might be difficult to live with.

Signs or symptoms of work-related stress can be physical, psychological (emotional and cognitive) and behavioural. They are summarized in the table below (table 3).

Table 3. Symptoms of work-related stress

\begin{tabular}{|l|l|}
\hline Physical symptoms & \multicolumn{2}{|l|}{ Emotional symptoms } \\
- Fatigue & - Guilt \\
- Sleep disorders & - Irritability \\
- Chest pain & - Anxiety \\
- Neck / back pain & - Feeling of loneliness \\
- Gastrointestinal disorders & - Fury \\
- Appetite disorders & - Depression \\
- Headache & - Shock \\
- Dizziness & - Sadness \\
- Muscle tension & - Feeling overwhelmed \\
- Increased risk of flu / colds & Behavioural symptoms \\
Cognitive symptoms & - Increasing requests for days off / \\
- Denial & - sick leave \\
- Lack of concentration & - Increased alcohol / drug use \\
- Flashbacks & - Withdrawal \\
- Altering the perspective on life & - Increased risk of accidents \\
- Short-term memory problems & - Antisocial acts / problems in \\
- Difficulties in solving & - interpersonal relationships \\
- problems & - Hypervigilance \\
- Blaming others & Decreased work performance \\
- Difficulty in making decisions &
\end{tabular}

\section{Managing and preventing work-related stress}

In the field of workplace stress management, interventions can be classified as primary, secondary or tertiary. Primary interventions are preventive, aiming to prevent exposure to stressors and the occurrence of diseases among employees. Most preventive interventions are organizational approaches, but can also be individual approaches, such as the development of conflict management skills. Secondary interventions are ameliorating and their main 
purpose is to change the individual's response to stress by increasing awareness, knowledge, skills and resources of stress management. Tertiary interventions are reactive, they have the role of reducing as much as possible the effects of stress, once they have occurred, by managing the symptoms. (Fig. 2)

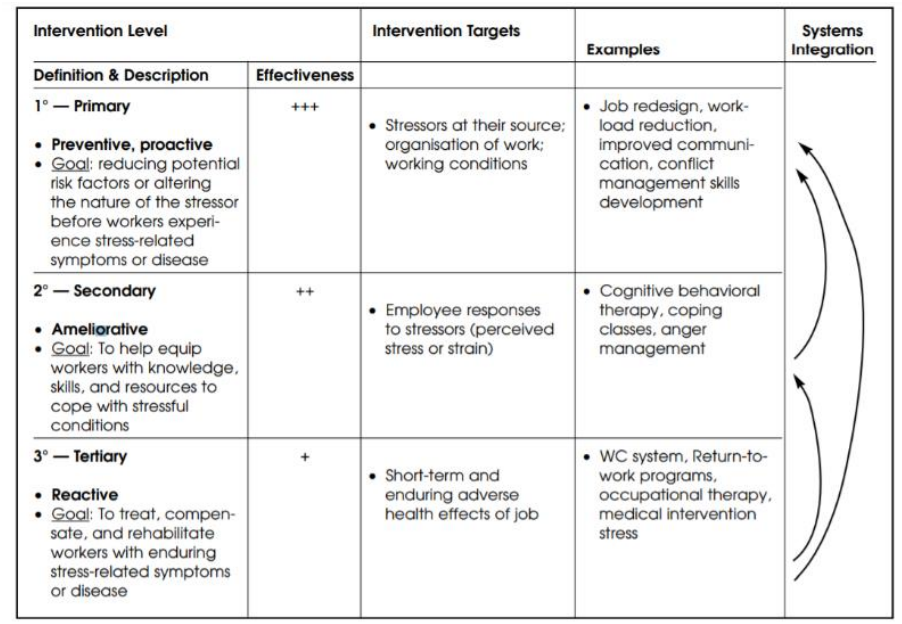

Fig. 2. A Systems Approach to Job Stress [7]

Most commonly, stress management involves secondary and tertiary interventions that ideally identify problems that should return to primary prevention [7]. Some examples include: stress education in order to help employees recognize symptoms and reduce stigma, stress management training. All these aspects can be brought together under the name of psychological training of personnel.

In the context of intervention and rescue activities in toxic / flammable / explosive environments, psychological training can help individuals think more clearly and reduce the risk of serious injury and loss of life or material loss. It is unrealistic to think that individuals can be fully emotionally prepared to deal with any type of intervention and rescue situation. However, psychological training can help in coping with the stress caused by unforeseen situations and can also help reduce stress after the intervention. Being psychologically prepared also implies realistic expectations that an emergency situation can very quickly become unmanageable, unpredictable and life-threatening.

Psychological training in the workplace should help emergency response personnel to cope with the emotional burden of their work [8]. Possible primary prevention measures include:

- As much adequate information as possible, regarding the nature of the disaster, the number and location of affected people, what other intervention and rescue personnel are on site, etc. Information on site's conditions should be as complete as possible.

- Stimulating the internal locus of control of intervention personnel could help them to perform their tasks without further affecting their mental health. Self-esteem, self-confidence and self-image are all factors that impact how an individual manages stress reactions during and after a traumatic event.

- Experiencing feelings of confidence and security can act as a buffer for negative stress reactions. Social support from family and colleagues and a well-developed personal support network can help intervention and rescue staff get over traumatic events more easily.

- Well-coordinated teamwork, with the support of colleagues, provides a sense of security and belonging, reducing mental and emotional strain at event site. Since experienced 
personnel appear to be less at risk for mental health problems, teams of personnel with varying degrees of experience could provide increased social support for the less experienced. Skills training techniques start from the assumption that a person who develops their skills will be able to cope more easily with different situations they will face, therefore training programs are implemented to develop social skills, communication skills or problem solving.

- An individual's ability to cope with difficult emotions and stress can also be improved through psychological training in stress management, relaxation techniques and cognitivebehavioural techniques that can be used when making decisions under pressure. Relaxation techniques are based on the idea that the person is able to change a number of physiological parameters whose activity in stressful situations tends to increase greatly, therefore he is taught to breathe more deeply, to meditate and to engage in physical activities or perform various self-suggestion exercises, guided imagery and yoga.

- Techniques for monitoring stressors and symptoms, which start from the assumption that the person will avoid stress if he becomes aware of the situations that cause stress reactions.

- Stress tolerance techniques, which start from the certainty that stress is inherent in life, and people's response to events is mediated by their cognitive interpretation, therefore the idea of trying to help the person to change how they appreciate events. Different cognitivebehavioural techniques are used, such as cognitive restructuring, cognitive assessment, stress inoculation, etc.

Also, there are studies $[9,10,11]$ that show that improving psychological personality traits, such as the sense of coherence, resilience, and the ability to psychologically adapt, can facilitate coping with difficult, traumatic situations. The feeling of coherence is related to intelligibility (perceiving the world as being easy to understand), flexibility (taking into account all the appropriate and efficient resources available to manage or control life events effectively) and meaning (feeling that it makes sense to care about what happens, that it is really worth the effort and it is satisfying). Robustness defines people with a high level of commitment, control, responsibility, who treat challenges as opportunities for personal development. Resilience can be defined as the ability of each individual to use the available psychological, social, cultural, and physical resources to sustain well-being, and also the ability to obtain those resources. In the workplace these characteristics can be improved through team cohesion, collective identity, common values, good leadership, trust and mission objectives (goal orientation).

\section{Conclusions}

Occupational psychosocial risks are among the main emerging health and safety risks, and exposure to them can affect the employee's health, both psychologically and physically, through a stress-mediated pathway. Excessive stress is linked to poor performance, a higher rate of absenteeism and accidents, physical and emotional health problems of workers.

Sources of stress are various, being related to work environment aspects, personal factors and the family environment. In general, stress as a system can be seen as fluctuating, open, dynamic and constantly changing. Furthermore, the consequences of a stressful event can be exacerbated by a multitude of everyday events, such as the individual's resources, the interpretation he gives to the situation, the meanings and symbols attached to the experience, the opportunity or ability to act on the environment, support system, etc.

Intervention and rescue activity is characterized by high workload and intense time pressure, coping with injury and death, the need to suppress emotions during work and yet to be at the same time full of empathy, characteristics that can be risk factors for the phenomenon of occupational stress. 
Psychological training involves processes and abilities such as knowledge, anticipatory processes, recognition, arousal, thinking, emotions, intentions, decision making, and the management of thoughts, emotions, and actions. A better understanding of one's own psychological response and that of others helps individuals to feel more confident, to have more control, and to be better prepared, both psychologically and in terms of effective work planning. Psychological training can help individuals think clearly and rationally, which leads, in the context of intervention and rescue activities in toxic / flammable / explosive environments, to reduce the risk of serious injury and loss of life, thus contributing to the increase of the level of occupational health and safety.

\section{References}

1. EU-OSHA, ESENER 2019, Third European Survey of Enterprises on New and Emerging, online at: https://visualisation.osha.europa.eu/esener\#!/en/survey/overview/2019

2. J. C. Thomas, M. Hersen, Handbook of Mental Health in the Workplace, Sage Publications, pp. 47, (2002)

3. J. de Jonge, M.F. Dollard, C Dormann et al., The Demand-Control Model: Specific Demands, Specific Control and Well-Defined Groups, International Journal of Stress Management 7, 269-287 (2000)

4. R. M. Iordache V. Petreanu, M. Ignat, The "effort - reward imbalance" model in organizational psychology, Psychology, vol. 58 (4), 307-314, (2012)

5. S. Folkman, R. S.Lazarus, C. Dunkel-Schetter, A. DeLongis, R. J. Gruen, Dynamics of a stressful encounter: Cognitive appraisal, coping, and encounter outcomes. Journal of Personality and Social Psychology, 50(5), 992-1003. (1986)

6. T. Cox, Stress Research and Stress Management: Putting Theory to Work, Health and Safety Executive, pp. 36, (1993)

7. A.D. LaMontagne, T. Keegel, A.M.L. Louie, A. Ostry, P.A. Landsbergis, A systematic review of the job-stress intervention evaluation literature, 1995-2005, International Journal of Occupational Environmental Health, Vol. 13, pp. 268-280, (2007)

8. I. Kovacs, G. A. Gaman, D. Pupazan, et al, Psychological training program for intervention and rescue personnel, Environmental engineering and management journal, 18 (4), 853-864, (2019)

9. I.B. Iamandescu, Mental stress and internal diseases, All Publishing House, Bucharest, (2002)

10. R.S. Lazarus, Psychological Stress and the Coping Process, McGraw-Hill Book Co, New York, (1966)

11. M. Smith, D. Saklofske, K. Keefer, P. Tremblay, Coping Strategies and Psychological Outcomes: The Moderating Effects of Personal Resiliency, The Journal of psychology, 150(3), 318-332, (2016) 